\title{
FURTHER RESULTS ON VALUE DISTRIBUTION OF L-FUNCTIONS
}

\author{
HaRina P. WAGHAMORE AND S. H. NAVEENKUMAR
}

Abstract. With the aid of weighted sharing we study the uniqueness of meromorphic functions concerning nonlinear differential polynomials that share a nonzero polynomial with the same of L-functions. Our results in the paper will improve, extend a results due to Fang Liu, Xiao-Min Li and Hong-Xun Yi [5].

Mathematics subject classification (2010): Primary 30D35.

Keywords and phrases: Nevanlinna theory, L-functions, meromorphic function, sharing values, differential polynomial.

\section{REFERENCES}

[1] A. BAnERJEe, Meromorphic functions sharing one value, Int. J. Math.Math. Sci. 22, (2005), 35873598.

[2] A. Banerjee, On a question of Gross, J. Math. Anal. Appl. 327, (2007), no. 2, 1273-1283.

[3] A. BANERJEe AND GoutAm Haldar, Certain non-linear differential polynomials having common poles sharing a non zero polynomial with finite weight, Journal of Classical Analysis 6, Number 2 (2015), 167-190.

[4] M.-L. FANG, Uniqueness and value-sharing of entire functions, Comput. Math. Appl. 44 (2002), no. 5-6, 823-831.

[5] Fang LiU, XiaO-Min LI AND Hong-Xun YI, Value distribution of L-functions concerning shared values, Proc. Japan Acad. 93, Ser. A (2017).

[6] Harina P. Waghamore AND V. HuSna, Generalization on uniqueness of meromorphic functions of a certain differential polynomials, J. Class. Anal. 9, (2016), no. 1, 27-34.

[7] HARINA P. WAGHAMORE AND S. RAJESHWARI, Weighted sharing of non-linear differential polynomials sharing small function with regard to multiplicity, J. Class. Anal. 10, (2017), no. 1, 1-14.

[8] W. K. Hayman, Meromorphic functions, Oxford Mathematical Monographs, Clarendon Press, Oxford, 1964.

[9] W. K. Hayman And J. Miles, On the growth of a meromorphic function and its derivatives, Complex Variables Theory Appl. 12 (1989), no. 1-4, 245-260.

[10] Q. HAN, Some uniqueness results related to L-functions, Boll. Unione Mat. Ital. 10, (2017), 503-515.

[11] Jun-Feng XU, FEng LU AND Hong-XUn YI, Fixed-points and uniqueness of meromorphic functions, Computers and Mathematics with Applications 59, (2010) 9-17.

[12] I. LAHIRI, Uniqueness of meromorphic functions as governed by their differential polynomials, Yokohama Math. J. 44 (1997), no. 2, 147-156.

[13] I. LAHIRI, Weighted sharing of three values and uniqueness of meromorphic functions, Kodai Math. J. 24 (2001), no. 3, 421-435.

[14] I. Lahiri, On a question of Hong Xun Yi, Arch. Math. (Brno), 38, (2002), 119-128.

[15] I. LAINE, Nevanlinna theory and complex differential equations, de Gruyter Studies in Mathematics 15, de Gruyter, Berlin, 1993.

[16] P. Li AND C. C. YANG, On the characteristics of meromorphic functions that share three values CM, J. Math. Anal. Appl. 220, (1998), 132-145.

[17] B. Q. LI, A result on value distribution of L-functions, Proc. Amer. Math. Soc. 138 (2010), no. 6, 2071-2077.

[18] W. C. Lin AND P. Q. LIN, Uniqueness theorems of L-functions, Acta Math. Sinica, Chinese Series, 61 (2018), no. 4, 601-608. 
[19] X.-M. LI AND H.-X. YI, Uniqueness of meromorphic functions whose certain nonlinear differential polynomials share a polynomial, Comput. Math. Appl. 62 (2011), no. 2, 539-550.

[20] C. MENG, Uniqueness of meromorphic functions sharing one value, Applied Mathematics E-Notes 7, (2007), 199-205.

[21] C. MEng, Value sharing of entire functions, Applied Mathematics E-Notes 8, (2008), 179-185.

[22] A. Z. Mokнonko, On the Nevanlinna characteristics of some meromorphic functions, in Theory of Functions, Functional Analysis and their Applications 14, Izdvo Khar'kovsk, Unta, 1971, pp. 83-87.

[23] R. Nevanlinna, Einige Eindeutigkeitssatze in der Theorie der Meromorphen Funktionen, Acta Math 48 (1926), no. 3-4, 367-391.

[24] A. Selberg, Old and new conjectures and results about a class of Dirichlet series, Proceedings of the Amalfi Conference on Analytic Number Theory (Maiori, 1989), 367-385, Univ. Salerno, Salerno, 1992.

[25] J. Steuding, Value-distribution of L-functions, Lecture Notes in Mathematics, 1877, Springer, Berlin, 2007.

[26] J. M. Whittaker, The order of the derivative of a meromorphic function, J. London Math. Soc. S1-11 (1936), no. 2, 82-87.

[27] L. Q. WANG AND X. D. LUO, Uniqueness of meromorphic functions concerning fixed points, Math. Slovaca 62, 1 (2012), 29-38.

[28] C.-C. YAng AND X. HUA, Uniqueness and value sharing of meromorphic functions, Ann. Acad. Sci. Fenn. Math. 22 (1997), no. 2, 395-406.

[29] C.-C. YANG AND H.-X. YI, Uniqueness theory of meromorphic functions, Mathematics and its Applications 557, Kluwer Acad. Publ., Dordrecht, 2003.

[30] L. YANG, Normality for families of meromorphic functions, Sci. Sinica Ser. A, 29 (1986), no. 12, 1263-1274.

[31] L. YANG, Value distribution theory, translated and revised from the 1982 Chinese original, Springer, Berlin, 1993.

[32] Q. C. Zhang, Meromorphic functions sharing three values, Indian J. Pure Appl. Math. 30 (1999), no. 7, 667-682.

[33] Q. C. ZHANG, Meromorphic function that shares one small function with its derivative, J. Inequal. Pure Appl. Math. 6, 4 (2005), Art.116, http://jipam.vu.edu.au/. 